\title{
Role of Safety and Health Awareness in Occupational Safety and Health Performance in Public Health Facilities in Machakos County, Kenya
}

\author{
Patrick Kinyanjui Njogu", *, Charles Mburu², Benson Karanja ${ }^{2}$ \\ ${ }^{1}$ Department of Health, Nyeri County, Kenya \\ ${ }^{2}$ Institute of Energy and Environmental Technology, Jomo Kenyatta University of Agriculture and Technology, Juja, Kenya
}

Email address:

njogupatrick@gmail.com (P. K. Njogu)

${ }^{*}$ Corresponding author

\section{To cite this article:}

Patrick Kinyanjui Njogu, Charles Mburu, Benson Karanja. Role of Safety and Health Awareness in Occupational Safety and Health Performance in Public Health Facilities in Machakos County, Kenya. Journal of Health and Environmental Research.

Vol. 5, No. 1, 2019, pp. 1-7. doi: 10.11648/j.jher.20190501.11

Received: January 3, 2019; Accepted: January 29, 2019; Published: February 22, 2019

\begin{abstract}
The Kenya Occupational Safety and Health Act (OSHA) obligates employers to ensure the provision of occupational safety and health information and training to all persons in their workplaces. In spite of this requirement, the risk of occupational exposures among the healthcare workers remains high. The researchers aimed to determine whether occupational safety and health (OSH) awareness among health workers and health management hindered implementation of OSHA in public dispensaries and health centres, using Machakos County. The study was a cross-sectional descriptive survey conducted in February 2018 and involved 107 health workers in public dispensaries and health centres and 42 members of the Health Management in Machakos County. It involved physical observations, collection of data from respondents, and analysis of the data. Linear regression results indicated strong negative relationship between OSH awareness and hindrance in the implementation of OSHA. The prediction factor was $-0.6400, p<0.05$. These showed that one unit increase in OSH awareness predicted a decrease of 0.64 units of hindrance in the implementation of OSH Act. The null hypothesis, Implementation of Occupational Safety and Health Act is not affected by OSH awareness among health workers and health management, failed in favour the alternative hypothesis. The researchers concluded that lack of OSH awareness among health workers and management hindered implementation of OSHA in the selected facilities. The health workers and management should be trained in OSH. Regular OSH refresher seminars should be conducted and OSH information disseminated and displayed throughout the health facilities. OSH policy should be communicated through trainings and displays in health facilities.
\end{abstract}

Keywords: Role, Safety and Health Awareness, Occupational Safety and Health Performance, Public Health Facilities, Machakos County

\section{Introduction}

Occupational safety and health (OSH) focusses on the prevention of work-related injuries and illnesses through the provision of suitable conditions of employment to attain the highest level of health of all workers [1]. This deliberate mandate of the International Labour Organization (ILO) aims to ensure that safety and health of workers is not disregarded and that the workers do not lose employment due to occupational illness or injury [2]. Health workers are more than 50 million worldwide [3] and they must be protected from the various work hazards [4] which they often face [5]. Healthcare workers are exposed to harmful physical, chemical and biological agents as well as violence, lethargy, and musculoskeletal strains [6].

The annual rates of absenteeism associated with workrelated injuries or illnesses and the probability of being injured in healthcare settings are higher than in other sectors [7]. The incidence of occupational illnesses and injuries in hospitals of the United States (US) was 68 cases per 1000 regular employees in the year 2011 [7]. In the US, Healthcare-Associated Infections (HAIs) in excess of 1.7 million and 99,000 related deaths occur annually [8]. HAIs 
are estimated to account for approximately $10 \%$ of hospital admissions and up to $31 \%$ in countries with constrained resources [9]. While implementation of OSH policy in a workplace is a primary strategy for the reduction of occupational safety and health problems [10], it is less common in healthcare settings than in other sectors [11]. Relevant legislations and guidelines are set up, but a majority of institutions fail to apply them adequately [12].

Training is a fundamental element in the management of occupational safety and health [5]. It aims to guarantee and enhance understanding of occupational safety and health among workers, managers, and supervisors [13]. The Management needs to understand the relevant legislation and effective OSH management, while workers should understand work hazards and safe work practices [14]. Familiarity with work hazards contributes to safer work practices in workplaces [15]. OSH awareness makes individuals fit into their work by acquiring the required skills and knowledge and this helps in making appropriate decisions, and in the achievement and sustenance of good working conditions and environments [5].

The Kenya Occupational Safety and Health Act [16] mandates employers to ensure the provision of $\mathrm{OSH}$ information and training to all persons in the workplaces. The health sector occupational safety health policy [17] compels the health management at all levels to provide and communicate safety and health instructions and guidelines for the work tasks, and monitor compliance with them in the workplaces. The policy further requires the health managers to provide specialized training in occupational safety and health to health workers and allocate of financial resources for OSH activities. However, work-related incidents persist in Kenyan health sector [18]. The risk of occupational exposures among the healthcare workers is high [19]. Not much research is published about the effects of $\mathrm{OSH}$ awareness among health workers and management on the implementation of occupational safety and health Act in public health facilities. The researchers attempted to fill this gap using Machakos County, Kenya.

The study targeted health workers in public dispensaries and health centres and health management teams in Machakos County only. The researchers included only those health workers who had worked in the sampled facilities for at least six months; and the Sub-County health management teams who were responsible for the sampled health facilities; and all members of the County health management team.

\section{Methods}

\subsection{Research Design}

The study was a cross-sectional descriptive survey conducted on approximately 800 healthcare workers in public dispensaries and health centres and 72 members of the health management in Machakos County. Questionnaires with Likert-scaled questions in the form of positive statements were used to obtain scored responses from respondents. Respondents were asked to indicate their level of agreement with each of the listed statements using the scale of (5-Strongly agree; 4-Agree; 3-Neutral; 2-Disagree; 1-Strongly disagree). For each of the statements, the participants were requested to indicate the extent to which in their opinion each of the practices affected implementation of occupational safety and health Act in their facility, using the scale of (1-Very small extent, 2-Small extent, 3-Moderate extent, 4-Large Extent, 5-Very large extent). A pilot study was conducted and the results utilized to compute Cronbach's alpha to assess the validity of the questionnaires. Photography and checklists were used to record observations in the facilities, such as documents review and displayed OSH information. All the data collected were summarized in tables and analyzed. T-test was used to test hypothesis.

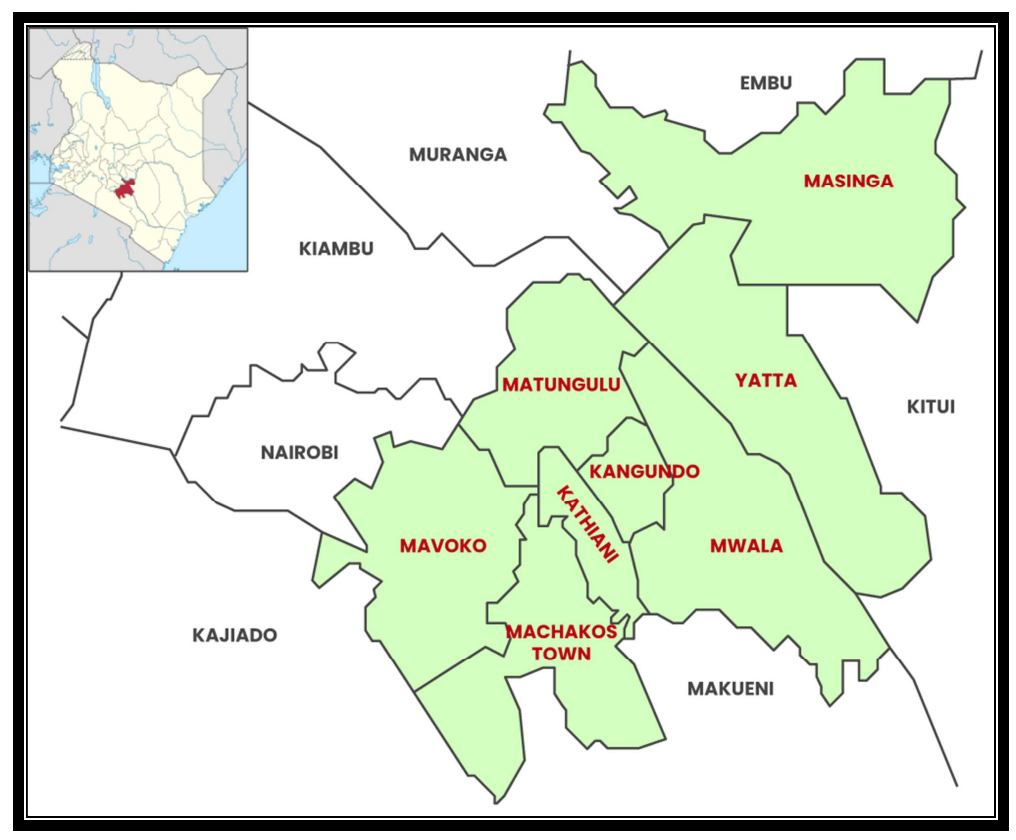

Figure 1. Map of Machakos County [20]. 


\subsection{Sample Size Determination}

To calculate the sample size for the health workers, the researchers applied Naissuma (2000) [21] formula:

$$
\mathrm{n}=\mathrm{Nc}^{2} / \mathrm{c}^{2}+(\mathrm{N}-1) \mathrm{e}^{2}
$$

Where:

$\mathrm{n}=$ Sample size

$\mathrm{N}=$ Population

$\mathrm{c}=$ Coefficient of Variation $(\mathrm{CV})$

$\mathrm{e}=$ Standard error

According to Naissuma, a coefficient of variation of between $21 \%<\mathrm{e}<30 \%$ is acceptable in most surveys. The researchers used the highest coefficient of variation to ensure that sample size was as big and representative as possible. The lowest limit of standard error was used to minimize the degree of error. A coefficient variation of $30 \%(0.3)$ and a standard error of $3 \%$ $(0.03)$, therefore, applied in this study as below:

$$
\begin{aligned}
& \mathrm{n}=\mathrm{Nc}^{2} / \mathrm{c}^{2}+(\mathrm{N}-1) \mathrm{e}^{2} \\
& \mathrm{n}=800 \times 0.3^{2} /\left[0.3^{2}+(800-1) 0.03^{2}\right] \\
& \mathrm{n}=72 / 0.8091 \\
& \mathrm{n}=89 .
\end{aligned}
$$

The researcher increased the sample size by $20 \%$, to 107 , purposely to ensure that those eligible respondents in the sampled facilities who could be off-duty and those unwilling to participate would not affect the representativeness of the sample. This was more than $13 \%$ of the study population. $10 \%$ of the targeted study population is a sufficient sample size in a survey [22]. The sample was allocated proportionately to respondents' categories based on their population in dispensaries and health centres within the study area:

Number of respondents desired per category $\left(\mathrm{n}_{1}\right)=X n / N$

Where: $\mathrm{n}=$ Desired sample size in the study area

$\mathrm{X}=$ Number of the health workers in each category.

$\mathrm{N}=$ Total target population in the study area.

The sample included 88 nurses, 11clinical offices, and 8 laboratory staff.

\subsection{Sampling Methods}

Multistage sampling involving stratified, simple random and consecutive methods were applied on health workers. Stratified sampling was used to distribute respondents proportionately according to their category and number in the county. Based on the health facility staffing norms [23], stratified and simple random sampling were employed to determine the health facilities to include. The norms provide the categories and number of workers expected in the various levels of health facilities. Consecutive sampling was adopted to select the health workers to interview in the sampled health facility. Members of the County and Sub-county health management teams, who were available and willing to participate, were included. Only

\begin{tabular}{|c|c|c|c|c|c|c|c|}
\hline Statements & 5 & 4 & 3 & 2 & 1 & Mean & SD \\
\hline You have received a OSH specific training & 5 & 11 & 20 & 30 & 24 & 2.37 & 0.753 \\
\hline Regular refresher seminars on Occupational Safety and Health are conducted in the facility & 6 & 10 & 21 & 30 & 23 & 2.40 & 0.756 \\
\hline You understand your workplace hazards well & 7 & 9 & 20 & 32 & 22 & 2.41 & 0.744 \\
\hline There are safety and health guidelines for all the various work tasks in the facility & 6 & 11 & 22 & 29 & 22 & 2.44 & 0.751 \\
\hline Safety and health information is adequately communicated throughout the facility & 4 & 12 & 24 & 29 & 21 & 2.43 & 0.738 \\
\hline Aggregate & & & & & & 2.41 & 0.748 \\
\hline
\end{tabular}
the Sub-County health management teams responsible for the sampled health facilities were included in the study.

\section{Results and Discussion}

Table 1. Occupational Safety and Health Awareness among the Health Workers.

From Table 1 above, the aggregate mean was 2.41 (48.4\%). The range of deviations of each item mean from the aggregate mean was between -0.04 and +0.03 . Occupational safety and health training among the respondents recorded the lowest mean, 2.37 (47.4\%). Availability of safety and health guidelines for the various work tasks posted the highest mean, 2.44 (48.8\%). The aggregate standard deviation was 0.748 with deviations ranging between -0.01 and +0.01 . These results indicated good agreement among the respondents. Communication of safety and health

\begin{tabular}{|c|c|c|c|c|c|c|c|}
\hline Statements & 5 & 4 & 3 & 2 & 1 & Mean & SD \\
\hline The facility has a copy of OSH policy & 5 & 10 & 20 & 31 & 24 & 2.34 & 0.749 \\
\hline You understand the OSH Policy well & 5 & 11 & 20 & 30 & 24 & 2.37 & 0.753 \\
\hline Regular training sessions are held to communicate the OSH Policy to all persons in the facility & 4 & 10 & 21 & 30 & 25 & 2.31 & 0.742 \\
\hline The Policy is displayed throughout the facility & 3 & 8 & 21 & 33 & 25 & 2.30 & 0.661 \\
\hline Every health worker is provided with a copy of the Policy & 2 & 9 & 25 & 32 & 22 & 2.32 & 0.667 \\
\hline Aggregate & & & & & & 2.33 & 0.714 \\
\hline
\end{tabular}
information in health facilities had the highest agreement among the respondents $(\mathrm{SD}=0.738)$ while refresher seminars on $\mathrm{OSH}$ posted the lowest agreement $(\mathrm{SD}=0.756)$.

Table 2. Health Workers' Awareness of the Health Sector OSH Policy.

The aggregate mean was $2.33(46.6 \%)$ while the aggregate standard deviation was 0.714 . The range of deviations from the aggregate mean was between -0.03 and +0.04 . The range of deviations from the aggregate mean between -0.03 and 
+0.04 while that of standard deviations from the aggregate standard deviation was between -0.05 and +0.04 . These results indicated that the respondents agreed well about their level of awareness of the health sector OSH policy.

According to the results, training on OSH policy had a mean of 2.31, but documents review did not find any record of such trainings. OSH Policy displays within the facilities had a mean of 2.30 but these displays were not found during on-shop-floor checks conducted in the health workplaces. Having a copy of the policy scored a mean of 2.32 but none of the respondents identified the policy positively among other documents displayed by the researcher with the book titles covered.

The OSH Act mandates every organization to prepare its OSH policy and ensure it is communicated to all persons in the workplace. The health sector OSH policy provides that it should be disseminated through training and displays throughout the health facilities. These findings indicated that the health workers were not familiar with the health sector OSH policy.

Table 3. Occupational Safety and Health Awareness within the Health Management.

\begin{tabular}{|c|c|c|c|c|c|c|c|}
\hline Statements & 5 & 4 & 3 & 2 & 1 & Mean & SD \\
\hline You have received a training specifically on OSH & 1 & 3 & 10 & 11 & 7 & 2.38 & 0.664 \\
\hline Regular refresher seminars on OSH are conducted in your workplaces & 1 & 4 & 9 & 10 & 8 & 2.38 & 0.704 \\
\hline You understand hazards in your workplaces well & 1 & 5 & 10 & 8 & 8 & 2.47 & 0.711 \\
\hline You understand the Health Sector OSH Policy guidelines well & 0 & 3 & 11 & 11 & 7 & 2.31 & 0.603 \\
\hline You understand the Occupational Safety and Health Act well & 1 & 3 & 10 & 10 & 8 & 2.34 & 0.685 \\
\hline There are safety and health guidelines for all the various work tasks in your health facilities & 2 & 3 & 10 & 9 & 8 & 2.44 & 0.733 \\
\hline Safety and health information is adequately communicated throughout your workplaces & 0 & 5 & 10 & 9 & 8 & 2.38 & 0.664 \\
\hline You regularly conduct your workplace OSH Audits & 1 & 3 & 11 & 10 & 7 & 2.41 & 0.662 \\
\hline Aggregate & & & & & & 2.39 & 0.681 \\
\hline
\end{tabular}

As shown in Table 3, the aggregate mean of OSH awareness among the members of Health Management was $2.39(47.8 \%)$ while the aggregate standard deviation was 0.681 with deviations ranging between -0.08 and +0.05 . These results indicated good agreement among the respondents. Understanding of the Health Sector OSH Policy guidelines had the lowest mean, 2.31 (46.2\%), while understanding of hazards in the workplaces had the highest mean, 2.47 (49.4\%). The highest agreement among the respondents was on the knowledge of health sector OSH Policy (SD = 0.603), while their lowest agreement was on the availability of safety and health guidelines for the various work tasks in the health facilities $(\mathrm{SD}=0.733)$.

\subsection{Occupational Safety and Health Training and Refresher Seminars}

From the results in Table 1, 5.6\% of the health workers strongly agreed that they had received a training specifically on occupational safety and health while $25.6 \%$ of them strongly disagreed. $12.2 \%$ of the respondents agreed, while $33.3 \%$ of them disagreed. $24.4 \%$ of the respondents were neutral. Specific training in occupational safety and health among health workers posted a mean of 2.37 . None of the respondents had a certificate of training specifically in $\mathrm{OSH}$ $40 \%$ of the health workers had certificates of participation in a training on Infection Prevention and Control, while $64.4 \%$ only claimed to have had an on-the-job training in Waste Management. The mean for OSH refresher seminars was 2.40 but there were no records of such seminars found during documents review.

As shown in Table 3, 3.1\% of the members of the Health Management strongly agreed they had received a specific training in occupational safety and health while $21.96 \%$ of them strongly disagreed. $9.4 \%$ of the respondents agreed while $34.4 \%$ of them disagreed. $31.3 \%$ of the respondents were neutral. Specific training in OSH scored a mean of 2.38. None of the respondents had a certificate of training in OSH. Only $3.1 \%$ of them claimed to be undertaking a postgraduate course in OSH. The Mean for OSH seminars was 2.38 according to responses from the health management but documents review did not reveal any record of such seminars.

These findings indicated that the health workers and management were not trained in $\mathrm{OSH}$ and there were no OSH seminars held in the health workplaces. The OSH Act [16] requires the employer to ensure the provision of the necessary OSH training and information to all persons in the workplace. The health sector OSH policy [17] requires all health workers to be given OSH specific training. The management is also obligated to ensure safety instructions are provided and refresher seminars conducted regularly in workplaces [16]. It was inferred that lack of OSH training among health workers and management affected implementation of OSH Act in the selected health facilities.

\subsection{Health Workers and Management Understanding of Workplace Hazards}

From Table 1, 7.8\% of the health workers strongly claimed that they understood their workplace hazards well, while $24.4 \%$ of them strongly disagreed. Among the respondents, $10.0 \%$ agreed, $35.5 \%$ disagreed, and $22.2 \%$ of them were neutral. According to the results, understanding of workplace hazards among the health workers scored a mean of 2.41 $(48.2 \%)$.

As shown in Table 3 above, $3.1 \%$ of the members of the health management, strongly claimed to understand hazards in their workplaces well, while $25.0 \%$ of them strongly disagreed. Approximately $15.6 \%$ of the respondents agreed, 
while $25.0 \%$ disagreed and $31.3 \%$ of them were neutral. According to the respondents, the mean for this element was $2.47(49.4 \%)$. Based on the results, the mean combined for this OSH component among the health workers and management was 2.44 (48.8\%). These findings showed that health workers and management did not understand their workplace hazards well. According to the OSH Act and the health sector OSH policy, the health management and workers should be familiarized with their workplace hazards. The researchers concluded that lack of knowledge of workplace hazards affected implementation of the Act.

\subsection{Safety and Health Standard Operation Procedures}

As illustrated in Table 1 above, $6.7 \%$ of the health workers strongly agreed that there were safety and health guidelines for the various job tasks in their respective facilities, while $24.4 \%$ of them strongly disagreed. Among the respondents, $12.2 \%$ agreed while $24.4 \%$ disagreed and $32.2 \%$ of them remained neutral. The results in Table 3 showed that $6.3 \%$ of the members of health management strongly agreed that there were safety and health guidelines for the various job tasks in their health facilities, while $25 \%$ of them strongly disagreed. About $9.4 \%$ of the respondents agreed while $28 \%$ disagreed and $31.3 \%$ of them were neutral. Implementation of this OSH component scored a mean combined of 2.44 (48.8\%) among both the health workers and Management. Documents review did not find these guidelines in the workplaces. About 14.3\% of the facilities had only standard operating procedures in their laboratories aimed at ensuring quality and reliability of diagnostic results. Both the OSH Act and the health sector OSH policy obligate the health management to establish and communicate safety and health guidelines for the various work tasks in their workplaces. These results showed that there were no safety and health guidelines for the various work tasks in the health facilities. This lack of OSH guidelines affected implementation of OSHA.

\subsection{Communication of Safety and Health Information}

From Table 1 above, $4.4 \%$ of the health workers strongly agreed that safety and health information was adequately communicated throughout their health facilities, while $23.3 \%$ of them strongly disagreed. Of the respondents, $13.3 \%$ agreed while $28.1 \%$ disagreed and $24.4 \%$ of them were neutral. Among the members of the health management as illustrated in Table 3 above, 6.3\% strongly agreed that safety and health information was adequately communicated throughout the facilities, while $25.0 \%$ of them strongly disagreed. Approximately $9.4 \%$ of the respondents agreed while $28.1 \%$ disagreed and $11.1 \%$ of them chose a neutral position. Performance of this OSH element scored a mean of $2.43(48.6 \%)$ and $2.38(47.4 \%)$ according the health workers and health management respectively. Physical observations by the researchers did not find any $\mathrm{OSH}$ information displayed in any of the facilities. Only four (4) facilities had "Fire Exit" signs scantly displayed. Both the OSHA and OSH policy provide that OSH information should be displayed throughout the workplaces. The results showed that OSH information was not communicated in the health facilities. Failure to communicate OSH information was construed to be affecting implementation of the Act.

\subsection{Awareness of Health Sector OSH Policy}

From Table 2 above, training on health sector OSH policy among health workers had a mean of 2.31 (46.2\%), but documents review failed to find any record of such training. OSH Policy displays within the facilities had a mean of 2.30 $(46.0 \%)$ according to the respondents. These displays were, however, not found during on-shop-floor checks conducted in the health workplaces. Having a copy of the policy scored a mean of $2.32(46.4 \%)$ but when the researcher asked the respondents to identify the policy among other documents displayed by researcher with their titles masked, none of them could. These findings demonstrated that the health workers did not understand the health sector OSH policy.

From Table 3, the health management's understanding of the sector OSH policy scored a mean of 2.31 (46.2\%), while that of Occupational Safety and Health Act, 2007 had a mean of $2.34(46.8 \%)$. Physical checks established that only $3.1 \%$ of the members of health management had a copy of Occupational Safety and Health Act, 2007. None of them recognized a copy the Health Sector OSH Policy among three books displayed by the researcher. According to the Act, the management should understand and maintain copies of the Act. The results indicated that the health management did not understand the health sector OSH policy and the Kenya OSHA, 2007 well.

The OSH Act mandates each organization to prepare its OSH policy and ensure it is communicated to all persons in the workplace. The health sector OSH policy provides that it should be disseminated through training and displays throughout the health facilities. The researcher deduced that lack of health workers' awareness of the health sector OSH policy affected the implementation of $\mathrm{OSH}$ Act in the selected facilities. Further, lack of understanding of OSHA and the health sector OSH policy among the health management also affected implementation of the Act.

\subsection{Competent Occupational Safety and Health Inspections and Audits}

Responses from the study participants indicated that the mean for OSH inspections and audits tied at 2.38 (47.6\%). However, documents review showed there was no inspection report by an OSH Officer or workplace OSH Audit report for any health facility. According to OSHA, DOSHS is responsible for conducting inspection and training in all workplaces. The Act further requires OSH audits to be carried out in all the workplaces by competent persons. The $\mathrm{OSH}$ policy requires health managements to ensure $\mathrm{OSH}$ audits are carried out in their facilities regularly. According to Health and Safety Executive [14], assessments of workplaces by competent people promote correct decision making processes and actions. These results revealed that there were 
no competent inspections and audits conducted in the health facilities. The researchers deduced that lack of expert inspections and audits affected the implementation of implementation of the Act.

\subsection{Linear Regression Analysis}

Simple linear regression results confirmed that there existed a direct and positive relationship between the $\mathrm{OSH}$ awareness and implementation of $\mathrm{OSH}$ Act. The prediction factor was $\mathrm{OSH}$ awareness $(0.6400, p<0.05)$. These results indicated that one unit increase in OSH awareness resulted in an increase of 0.64 units in the implementation of OSH Act. Conversely, the results showed that there existed a direct and negative relationship between OSH awareness and hindrance in the implementation of $\mathrm{OSH}$ Act. The prediction factors was, therefore, $-0.6400, p<0.05$. This implied that one unit increase in OSH awareness resulted in a decrease of 0.64 units of hindrance in the implementation of OSH Act.

\subsection{Hypothesis Testing}

The null hypothesis, Implementation of Occupational Safety and Health Act is not affected by OSH awareness among health workers and health management $\left(\mathrm{H}_{0}: \mu-3=0\right)$, failed in favour of the alternative hypothesis $\left(\mathrm{H}_{\mathrm{A}}: \mu-3 \neq 0\right)$. The computed t-statistics were more than the right-tail critical values, 12.9759 and 5.0671 compared with 1.662 at $\alpha$ $=0.05$ and 1.696 at $\alpha=0.05$ respectively.

\section{Conclusions}

Lack of OSH awareness among the management and workers hindered the implementation of OSH Act in public dispensaries and health centres. The mean for the awareness was 2.41 and 2.39 among the health workers and management, representing $48.2 \%$ and $47.8 \%$ respective level of awareness. The health workers and management had not been trained in OSH and there were no OSH seminars held. $\mathrm{OSH}$ information was not communicated and $\mathrm{OSH}$ guidelines for work tasks were not provided. Both the health management and the workers were not familiar with the health sector OSH Policy and the Kenya OSH Act. Occupational safety and health inspections and audits by independent experts were not carried out in the facilities. Simple regression analysis showed a unit increase in OSH awareness predicted a decrease of 0.64 units of hindrance in the implementation of OSH Act. The null hypothesis, implementation of OSH Act is not affected by OSH awareness among the health workers and management, failed in favour of the corresponding alternative hypothesis. The computed $t$ statistics for the OSH awareness among both the workers and management were more than the right-tail critical value of the $t$-distribution.

These findings were in agreement with Wambilianga \& Waiganjo (2015) [24] who argued that training affected compliance with OSH regulations. They also concurred with Kaaria (2015) [25] who concluded that training affected OSH implementation; and Rotich and Kwasira (2015) [26] who affirmed that sensitizing workers on an OSH programme was critical for its implementation. They further agreed with Oluoch et al (2017) [27] who concluded that occupational safety and health awareness affected workers' consciousness of their work environment.

\section{Recommendations}

Occupational safety and health training should be provided to all the health workers and members of the health management. The health management should sustain OSH awareness among all persons in the health workplaces by ensuring regular trainings and refresher seminars are carried out. Occupational safety and health information should be communicated to all persons and displayed throughout the health facilities. The health sector OSH policy should be disseminated through training and displays in the health facilities continuously. Competent OSH inspections and audits should be conducted in the health facilities regularly.

\section{Acknowledgements}

We, the researchers, sincerely appreciate the Machakos County Commissioner, County Director of Health Services, Sub-County medical officers, and the in-charges of health facilities studied for their consent to the study. Special thanks to all the research participants for their time and information provided. These persons and institutions made tremendous contribution to the success of this research.

\section{Conflict of Interest}

The researchers had no conflict of interest at all in the study.

\section{References}

[1] International Labor Organization (2001). Guidelines on Occupational Safety and Health Management Systems: Volume II. International Labor Office (ILO): Geneva.

[2] International Labor Organization (2010). Safety and Health at Work: International Labor Office (ILO): Geneva.

[3] World Health Organization (2016). Health Workforce Requirements for Universal Health Coverage and the Sustainable Development Goals: Human Resources for Health Observer, 17. Geneva: WHO.

[4] World Health Organization (2010). Health Worker Occupational Health. In: WHO (Ed) Occupational Health workers, Volume 2012. Geneva: WHO.

[5] Alli, B. O. (2008). Fundamental Principles of Occupational Health and Safety. Geneva: International Labor Office.

[6] European Union (2011). Occupational Health and Safety Risks in the Healthcare Sector: Guide to Prevention and Good Practice. Luxembourg: Publications Office of the European Union. 
[7] Occupational Safety and Health Administration (2013a). Safety and Health Management Systems: Facts about Hospital Worker Safety- New York: U.S. Department of Labor.

[8] Klevens, R. M., Edwards, J. R., Richards Jr, C. L., Horan, T. C., Gaynes, R. P., Pollock, D. A., \& Cardo, D. M. (2007). Estimating Health Care-Associated Infections and Deaths in US Hospitals, 2002. Public health reports, 122(2), 160-166.

[9] Ministry of Health (2010). National Infection Prevention and Control Guidelines for Health Care Services in Kenya: Nairobi: $\mathrm{MOH}$.

[10] Nshunju, R. K. (2012). Compliance to Occupational and Public Health Requirements and Associated Factors in Barbershops and Hair Dressing Salons, A Case of Kinondoni Municipality, Dar es Salaam, Tanzania (Doctoral dissertation, Muhimbili University of Health and Allied Sciences).

[11] Subhani, M. G. (2010). Study occupational health \& safety management system (OHSMS) in Universities' context and possibilities for its implementation: A case study of University of Gavle., Msc Thesis University of Gavle.

[12] Ndejjo, R., Musinguzi, G., Yu, X., Buregyeya, E., Musoke, D., Wang, J. S. \& Ssempebwa, J. (2015). Occupational Health Hazards among Healthcare Workers in Kampala, Uganda. Journal of Environmental and Public Health, 2015, 913741913741.

[13] Michigan Occupational Safety \& Health Administration (2011). Safety and Health Management System Guidelines: Consultation Education \& Training (CET) Division. Michigan (517) 322-1809.

[14] Health and Safety Executive (2008). Successful Health and Safety Management. Retrieved from: http://www.hse.gov.uk/pubns/books/hsg65.htm.

[15] Ndegwa, P. W. (2015). Perceptual Measures of Determinants of Implementation of Occupational Safety and Health Programmes in the Manufacturing Sector in Kenya (Doctoral dissertation).

[16] Government of Kenya (2007). Occupational Safety and Health Act. Kenya Law Reform Commission, Nairobi: Government Printer.

[17] Ministry of Health (2014a). Occupational safety and health policy guidelines for the health sector in Kenya. Nairobi: $\mathrm{MOH}$.

[18] Kenya Ministries of Health and IntraHealth International (2013). Report of the Occupational Safety and Health Risk Assessment. Nairobi: $\mathrm{MsOH}$.

[19] Ministry of Health (2016a). Occupational Exposure to Blood and Body Fluids and HIV Post-exposure Prophylaxis in Health Care Facilities in Kenya 2011 - 2014. Nairobi: MOH.

[20] Machakos CIDP (2015). County Integrated Development Plan, 2015. Retrieved from http://www.machakosgovernment.com/documents/CIDP.pdf.

[21] Naissuma, D. K. (2000). Survey Sampling Theory and Methods. Nairobi: Nairobi University Press.

[22] Mugenda, O. M \& Mugenda, A. G. (2003). Research Methods: Quantitative and Qualitative Approaches, Revised edition. Nairobi: Act press.

[23] Ministry of Health (2014b). Human Resources for Health Norms and Standards Guidelines for the Health Sector. Towards Universal Health Coverage: The Kenya Health Strategic and Investment Plan, 2014 - 2018. Nairobi: MOH.

[24] Wambilianga and Waiganjo (2015). Factors Influencing Compliance with Occupational Safety and Health Regulations in Public Hospitals in Kenya: A Case Study of Thika Level 5 Hospital.

[25] Kaaria, A. G. (2015). Factors Affecting the Implementation of Health and Safety in Supermarkets in Kenya. International Journal of Human Resource Studies, 5(2), 223-281.

[26] Rotich, L. C. \& Kwasira, J. (2015). Assessment of Success Factors in the Implementation of Occupational Health and Safety Programs in Tea Firms in Kenya: A Case of Kaisugu Tea Factory. International Journal of Economics, Commerce and Management. United Kingdom: Vol. III, 5, May 2015, ISSN 23480386.

[27] Oluoch, I. et al (2017). Effect of Occupational Safety and Health Awareness on Work Environment in the Water Service Industry within Kisumu County - Kenya. IOSR Journal of Environmental Science, Toxicology and Food Technology (IOSR-JESTFT).Volume 11, Issue 6 Ver. I (June. 2017), PP $35-41$ 